\title{
Betamethasone Attenuates Oxidant Stress in Endothelial Cells from Fetal Lambs with Persistent Pulmonary Hypertension
}

\author{
INDIRA CHANDRASEKAR, ANNIE EIS, AND GIRIJA G. KONDURI \\ Department of Pediatrics [I.C., A.E., G.G.K.], Cardiovascular Research Center [I.C., A.E., G.G.K.], Medical College of Wisconsin, \\ Milwaukee, Wisconsin, 53201; Zablocki VA Medical Center [G.G.K.], Milwaukee, Wisconsin, 53226
}

\begin{abstract}
We investigated the effects of betamethasone on oxidative stress and impaired vasodilation in a lamb model of persistent pulmonary hypertension (PPHN). We treated pregnant ewes following fetal ductal ligation with betamethasone or saline for $48 \mathrm{~h}$ before delivery. Response of fetal pulmonary arteries to nitric oxide synthase (NOS) agonist adenosine triphosphate (ATP) and nitric oxide (NO) donor, s-nitroso-n-acetyl-penicillamine (SNAP) was determined in tissue bath. Pulmonary artery endothelial cells (PAEC) from fetal lambs with ductal ligation or sham ligation were treated with betamethasone or its vehicle for $48 \mathrm{~h}$. Expression of endothelial NOS (eNOS), endothelin, endothelin-B (ET-B) receptor, and $\mathrm{CuZn}$ - and $\mathrm{Mn}$-superoxide dismutase (SOD) in PAEC was studied. Intracellular cGMP and superoxide levels and interaction of eNOS with heat shock protein 90 (Hsp90) were determined in PAEC. Antenatal betamethasone improved the relaxation response of pulmonary arteries to ATP and SNAP in PPHN. PPHN was associated with decreases in eNOS and ET-B receptor and increase in preproendothelin mRNA levels. Betamethasone decreased preproendothelin mRNA and ET-1 pro-peptide levels and increased eNOS and MnSOD protein levels in PPHN. Betamethasone reversed the increased superoxide/decreased cGMP levels and restored Hsp90eNOS interactions in PPHN. Betamethasone reduces oxidative stress and improves response of pulmonary arteries to vasodilators in lambs with PPHN. (Pediatr Res 63: 67-72, 2008)
\end{abstract}

$\mathrm{T}^{\mathrm{s}}$ he pulmonary vascular resistance (PVR) in the fetus undergoes a dramatic decrease at birth with the initiation of ventilation and oxygenation. Endothelium derived nitric oxide (NO) plays a major role in this birth-related transition $(1,2)$. Oxygen, adenosine triphosphate (ATP), and estrogen are important physiologic signals for activation of endothelial NO synthase (eNOS) at birth (2-5). Endothelium also regulates vascular tone with the release of potent vasoconstrictors, such as endothelin (6). Endothelin causes vasoconstriction and has biologic effects on NO release and smooth muscle growth $(7,8)$. Failure of PVR to decrease at birth results in persistent pulmonary hypertension of newborn (PPHN) and impaired oxygenation. PPHN is associated with decreased NO release and increased endothelin production, both of which contribute to impaired pulmonary vasodilation $(9,10)$. Recent studies in the fetal lamb model of PPHN induced by prenatal ligation of

Received February 2, 2007; accepted August 9, 2007

Correspondence: Girija G. Konduri, M.D., Associate Professor of Pediatrics, Medical College of Wisconsin, CCC Suite C410, PO Box 1997, Milwaukee, WI 53201-1997; e-mail: gkonduri@mcw.edu

Supported by grants RO1 HL57268 from the National Heart, Lung and Blood Institute and a grant in aid from American Heart Association, Northland affiliate (GGK). ductus arteriosus demonstrated a role for increased oxidative stress in the impaired pulmonary vasodilation $(11,12)$. Both NADPH oxidase and uncoupled eNOS contribute to the increased ROS in this model $(11,12)$. A coordinated regulation of endothelin and eNOS gene expression has been demonstrated in the ductal ligation model (13). Endothelin increases oxidant stress in PPHN (8) and inhibition of endothelin receptor-A attenuates pulmonary hypertension in fetal lambs (14). PPHN is also associated with a decrease in total superoxide dismutase (SOD) activity in pulmonary arteries (11). Thus, the impaired vasodilation in PPHN is associated with altered balance of pro- and antioxidant systems.

Glucocorticoids were previously shown to decrease oxidative stress in lungs in the presence of inflammation (15). Scavenging superoxide improves relaxation response of pulmonary arteries in PPHN to physiologic vasodilators, ATP, and NO (12). Prenatal glucocorticoids accelerate the late gestational rise in fetal rat and lamb lung antioxidant enzyme activity and decrease reactive oxygen species $(16,17)$. Antenatal betamethasone also improves relaxation responses to isoproterenol and prostaglandin E2 in pulmonary veins from fetal lambs (18). We therefore investigated the hypothesis that prenatal administration of betamethasone to fetal lambs with PPHN improves the relaxation response of pulmonary arteries to NOS agonist, ATP, and to NO donor, S-nitroso-n-acetylpenicillamine (SNAP). We also investigated the hypothesis that betamethasone exposure in vitro decreases oxidative stress and increases eNOS and SOD expression in pulmonary artery endothelial cells (PAEC) isolated from PPHN lambs.

\section{METHODS}

Creation of pphn model. This study was approved by the Animal Studies Subcommittee of Research and Development Committee of Zablocki Veterans Affairs Medical Center (Milwaukee, WI). The detailed methodology for creation of the ductal ligation model was reported previously (19). Briefly, fetal lambs underwent a left lateral thoracotomy under general anesthesia with $1-2 \%$ isoflurane administered to the ewe. The ductus arteriosus was identified and ligated with umbilical tape for creation of PPHN or left undisturbed for sham ligation, used as control. Fetal lungs were harvested after $8 \mathrm{~d}$ for isolation of pulmonary arteries and PAEC. Four fetal lambs each with ligation of PDA or sham procedure were used for isolation of PAEC. Eight fetal lambs with ductal ligation were also randomly assigned to receive either $12 \mathrm{mg}$ of

Abbreviations: eNOS, endothelial nitric oxide synthase; ET-Br, endothelin B receptor; Hsp90, heat shock protein 90; $\mathbf{O}_{2}^{-}$, superoxide; PPHN, persistent pulmonary hypertension of newborn; SNAP, S-nitroso-n-acetyl-penicillamine; SOD, superoxide dismutase 
betamethasone IM given to the ewe for two doses at 24-h intervals or equal volume of saline (vehicle) to simulate antenatal therapy given for mothers in preterm labor. The first dose was given $48 \mathrm{~h}$ before the planned delivery and harvest of fetal lungs.

Isolation and study of pulmonary artery rings. Details of methods for isolation and study of pulmonary arteries from fetal lambs in tissue bath were reported previously $(12,19)$. Third-fifth generation intrapulmonary arteries with an internal diameter of 300-500 $\mu \mathrm{M}$ were dissected and isolated from the lung. The arteries were cut into $1-\mathrm{mm}$ rings and were bathed in $2 \mathrm{~mL}$ of physiologic salt solution at $37^{\circ} \mathrm{C}$ and aerated to maintain normal acid-base status and oxygenation. They were stretched to a passive tension of $0.8 \mathrm{~g}$ and were preconstricted with $10^{-6}-10^{-7} \mathrm{M}$ norepinephrine. The tension reached with norepinephrine constriction for each ring was normalized to $100 \%$ and the percentage change with each dose of ATP or NO donor, SNAP (Sigma Chemical Co., St. Louis, MO) was expressed as mean \pm SD. Relaxation responses to $10^{-8}-10^{-3} \mathrm{M}$ doses of ATP and SNAP were determined.

Isolation and culture of endothelial cells. Pulmonary arteries were dissected into lung parenchyma up to the third-generation branches. Endothelial cells were isolated as described previously (12) with $0.1 \%$ collagenase type A (Roche Molecular Biochemicals, Indianapolis, IN). Endothelial cell identity was confirmed by acetylated LDL uptake and positive staining for factor VIII-related antigen $(12,19)$. Cells for individual experiments were grown to confluence in 100-mm dishes for RNA extraction, immunoprecipitation and Western blot studies, six-well plates for cGMP assays, or in micro wells of eight-well chamber glass slides (Lab-Tek II, Nalgene Inc., Naperville, IL) for assessment of superoxide $\left(\mathrm{O}_{2}^{-}\right)$levels using di-hydroethidine (DHE) fluorescence. PAEC were studied at passage 4 to maintain the phenotypical alteration produced by pulmonary hypertension in utero, as reported previously (19).

PAEC (approximately $60 \%$ confluent) were kept in low serum media (1\% FBS-DMEM) for an overnight period. The medium was then replaced with either 20\% FBS-DMEM or 20\% FBS-DMEM with betamethasone (Sigma Chemical Co.) at a concentration of $400 \mathrm{ng} / \mathrm{mL}\left(10^{-6} \mathrm{M}\right)$ for $48 \mathrm{~h}$. The concentration of betamethasone in media is based on plasma concentrations measured in pregnant sheep plasma (20) following a single injection of 0.25 $\mathrm{mg} / \mathrm{kg}$ (approximately $12 \mathrm{mg}$ for a 50-kg sheep) and are 10-20 fold higher than concentrations measured in fetal lambs (21).

Real-time quantitative $\boldsymbol{R}$ T-PCR. Total RNA was extracted from PAEC by Trizol RNA extraction according to the manufacturer's protocol (Invitrogen, Carlsbad, CA). Specific primers for eNOS, prepro-endothelin, and endothelin $\mathrm{B}$ receptor (ET-Br) were designed using Beacon Designer 2.0 software. Homology between different subtypes and the template secondary structure were carefully examined and avoided. The primers were designed to result in amplicons with a length of 75-150 bp. The sequence of primers is shown in Table 1. One microgram of total RNA was used for the reverse transcription to obtain cDNA. The mRNAs were reverse-transcribed into cDNAs by using a first strand superscript II cDNA synthesis kit (Invitrogen). The mRNA levels for eNOS, prepro-endothelin, and ET-Br were analyzed by real-time quantitative RT-PCR using a Bio-Rad iCycler system (Bio-Rad, Hercules, CA). Primers were optimized for temperature and primer concentration. Real-time PCR was performed by using a SYBR Supermix kit (Bio-Rad), and running for 40 cycles at $95^{\circ} \mathrm{C}$ for $20 \mathrm{~s}$ and $60^{\circ} \mathrm{C}$ for $1 \mathrm{~min}$. PCR efficiency was examined by serially diluting the template cDNA and the melting curve data collected to check the PCR specificity. Each cDNA sample was triplicated and the corresponding no-RT mRNA sample and no cDNA template were included as negative controls to verify genomic DNA contamination and nonspecific primer interactions, respectively. The $18 \mathrm{~s}$ rRNA primer was included in every plate as internal standard. The mRNA level of each sample for each primer set was normalized to that of the $18 \mathrm{~s}$ rRNA (22). Relative mRNA level was calculated per equation previously described by Pfaffl (22) for each gene of interest as $2^{\wedge}$ [(-delta delta $\left.\left.\mathrm{Ct}\right)\right]$ with control unstimulated cells as 1 and the fold increase/decrease from this value for each experimental condition shown as mean \pm SD from four separate experiments.

Table 1. Sequence of primers used for real time quantitative PCR analysis of $m R N A$ levels

\begin{tabular}{|c|c|c|}
\hline Gene & Primer type & Sequence \\
\hline \multirow[t]{2}{*}{ eNOS } & Sense & 5' CCTCACCGCTACAACATCC 3' \\
\hline & Anti-sense & 5' GCACAGCCAGGTTGATCTC 3' \\
\hline \multirow{2}{*}{$\begin{array}{l}\text { Pre-pro- } \\
\text { endothelin }\end{array}$} & Sense & 5' AGCCAGTCTTGTCTCCATCC 3' \\
\hline & Anti-sense & 5' TCTCCTCGCCTCCTCCAG 3' \\
\hline \multirow[t]{2}{*}{ ET-B Receptor } & Sense & 5' TTGCCTGGTCCTTGTCTTTG 3' \\
\hline & Anti-sense & 5' CCATGTTGATGCCAATGTAGT 3' \\
\hline \multirow[t]{2}{*}{$18 \mathrm{~s}$ rRNA } & Sense & 5' CGGACACGGACAGGATTGACAG 3' \\
\hline & Anti-sense & $5^{\prime}$ ATGCCAGAGTCTCGTTCGTTATCG 3' \\
\hline
\end{tabular}

Western analysis for proteins. Cells were lysed in modified RIPA buffer (23), which contains detergents and agents to solubilize membrane-associated proteins. The samples were sonicated, and insoluble cell debris was removed by centrifugation. The sample was heated to $70^{\circ} \mathrm{C}$ for $10 \mathrm{~min}$, and an aliquot of protein $(50 \mu \mathrm{g})$ was removed and resolved by SDS-PAGE (10\%). Separated proteins were transferred to nitrocellulose membranes and were blotted for eNOS with a specific antibody (9D10, Zymed Laboratories, South San Francisco, CA), MnSOD, CuZnSOD (Stressgen, Ann Arbor, MI), ET-B receptor (Abcam, Cambridge, MA), and $\beta 1$ subunit of soluble guanylate cyclase (sGC, Cayman Chemical, Ann Arbor, MI), overnight at $4^{\circ} \mathrm{C}$. Enhanced chemiluminescence (ECL) reagents (Amersham Pharmacia Biotech, Piscataway, NJ) were used to visualize bands. The autoradiographs were imaged with Adobe Photoshop 5.5 software and relative band densities quantified by Scion Image.

Co-precipitation studies for eNos heat shock protein (Hsp90). Confluent PAEC in 100-mm flasks were treated with Hank's buffered salt solution (HBSS) alone or with $10^{-5} \mathrm{M}$ ATP for $10 \mathrm{~min}$. Supernatant was then removed and cells were lysed in modified RIPA buffer $(23,24)$. Samples were sonicated and insoluble debris was removed by centrifugation. A $500-\mu \mathrm{g}$ aliquot of protein was used for immunoprecipitation with $\mathrm{H} 32$ antibody for eNOS (BIOMOL Research Laboratories, Plymouth Meeting, PA). The immunoprecipitated proteins were separated by SDS-PAGE (7.5-15\%) and transblotted to nitrocellulose membrane. The membranes were blocked with $5 \%$ nonfat milk in TBS-Tween $(0.1 \%)$ and then immunoblotted for eNOS and HSP90 with the use of appropriate antibodies [9D10, Zymed Laboratories and Transduction Laboratories (Lexington, KY), respectively]. The bands were visualized and quantified as described above.

cGMP-Assay in PAEC. PAEC in six-well plates were stimulated with ATP at $10^{-5} \mathrm{M}$ for $15 \mathrm{~min}$ followed by addition of cell lysis buffer (400 $\mu \mathrm{L} /$ well) containing $5 \%$ dodecyltrimethylammonium and $50 \mathrm{mM}$ sodium acetate, $\mathrm{pH}$ 5.8. The phosphodiesterase inhibitor, 3-isobutyl-1-methylxanthine (IBMX, $10^{-5} \mathrm{M}$ ) was added to all wells to prevent degradation of cGMP. The NOS inhibitor L-NAME was added to selected wells to provide a negative control for changes in cGMP levels. The intracellular cGMP concentration in the PAECs was determined using an enzyme immunoassay (EIA) kit (Amersham Pharmacia Biotech) per methods described previously (12). Protein concentration was measured in an aliquot of cell lysate. The cGMP levels in each well were normalized to protein concentration. Assays were performed in triplicate. The cGMP level per milligram of protein in control unstimulated well was normalized to $100 \%$ and percentage change with each condition was reported in the figures. Data are shown as mean \pm SD of four separate experiments.

Big endothelin-1 assay. Concentration of Big (pro) endothelin-1 (ET-1), stable precursor of ET-1 was measured in the control and PPHN PAEC treated with betamethasone by EIA method using a commercially available kit (Assay Designs Inc., Ann Arbor, MI). Protein concentration in each well was measured and the pro-ET-1 levels were expressed as picogram per milligram of protein. All data are mean \pm SD for four separate experiments each for control and PPHN cells.

Measurement of DHE fluorescence for $\mathrm{O}_{2}^{-}$levels. Cells were grown to confluence on Lab-Tek (Naperville, IL) eight-well chamber slides. Betamethasone treatment was done as above. Growth medium was removed and replaced with HBSS. Dihydroethidine (DHE, Invitrogen) was added to each well immediately followed by ATP, both at $10^{-5} \mathrm{M}$ concentration in preselected wells for $15 \mathrm{~min}$. Selected wells were treated with $1000 \mathrm{U} / \mathrm{mL}$ of SOD (Sigma Chemical Co.). Cells were washed with ice-cold HBSS, cover slipped, mounted, and visualized with a Nikon eclipse E600 microscope and images captured with spot RT slide camera (Diagnostic Instruments Inc., Sterling Heights, MI) and spot software v.3.5.9.1. DHE fluorescence was quantified using Metamorph software (Metavue, Universal Imaging Corporation, Downington, PA). Only fluorescence observed in excess of the wells treated with SOD was taken as indicative of $\mathrm{O}_{2}^{-}$level (SOD-inhibited DHE fluorescence). Data are shown as mean \pm SD of six separate experiments.

Statistical analysis. For comparisons between treatment groups, the null hypothesis was tested by a single-factor ANOVA for multiple groups or unpaired $t$ test for two groups. Significant differences $(p<0.05)$ between experimental groups were determined by Duncan's post hoc test for multiple comparisons.

\section{RESULTS}

Betamethasone effect on the relaxation response of pulmonary arteries. Pulmonary artery rings from PPHN lambs that received saline injections to the ewe failed to show relaxation responses to ATP and to NO donor, SNAP (Fig. 1), 

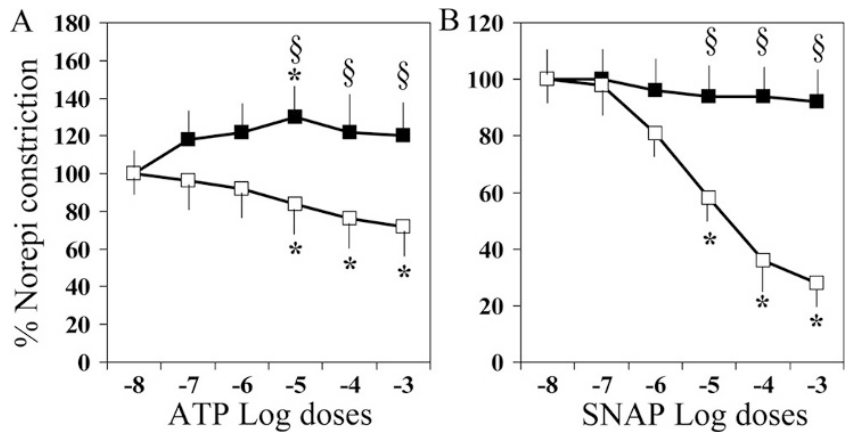

Figure 1. Effect of betamethasone (beta) on the relaxation response of pulmonary arteries from PPHN lambs to ATP $(A)$ and SNAP $(B)$. Data are mean $\pm \mathrm{SD}$ for 16 rings from four lambs each for antenatal betamethasone or saline. $* p<0.05$ from $10^{-8} \mathrm{M}$ dose; §from betamethasone group. ATP or SNAP alone ( $\square$ ); betamethasone + ATP or SNAP ( $\square$ ).
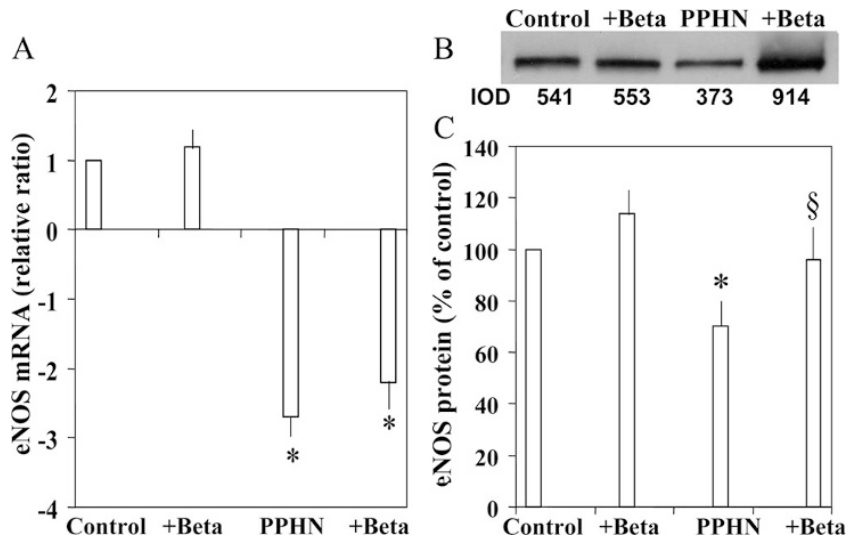

Figure 2. Effect of betamethasone (beta) on eNOS mRNA $(A)$ and protein levels $(B$ and $C$ ) in control and PPHN PAEC. Data for mRNA are fold increase/decrease from control untreated PAEC, which was normalized to 1. Summary data for protein levels $(C)$ are shown as percentage change from control PAEC. $* p<0.05$ from control PAEC; §from PPHN PAEC.

as reported previously (12). Pulmonary arteries from lambs that received antenatal betamethasone showed significant relaxation responses to both ATP and SNAP (Fig. 1).

Betamethasone effects on eNOS expression in PAEC. Compared with control PAEC, eNOS mRNA levels were decreased 2.5 fold in PPHN PAEC (Fig. 2A). Betamethasone treatment did not change eNOS mRNA levels significantly. The protein levels of eNOS were decreased in PAEC from PPHN lambs (Fig. 2, $B$ and $C$ ). Betamethasone increased eNOS protein levels in PPHN (Fig. 2, $B$ and $C$ ), suggesting that it preserves eNOS protein levels without affecting eNOS transcription.

Betamethasone effects on endothelin expression in PPHN. PAEC from PPHN lambs had a nearly 3-fold increase in preproendothelin mRNA compared with control PAEC (Fig. 3A). Betamethasone treatment resulted in a 2 -fold decrease in preproendothelin mRNA levels. ET-1 pro-peptide levels showed a trend for increase in PPHN compared with control cells, though the difference was not significant. Betamethasone treatment resulted in a nearly 7-fold decrease in the ET-1 pro-peptide levels in both control and PPHN cells (Fig. 3B). PAEC from PPHN lambs showed a 1.6-fold decrease in the mRNA levels for ET-B receptor (Fig. 4A). This was not corrected by betamethasone treatment.
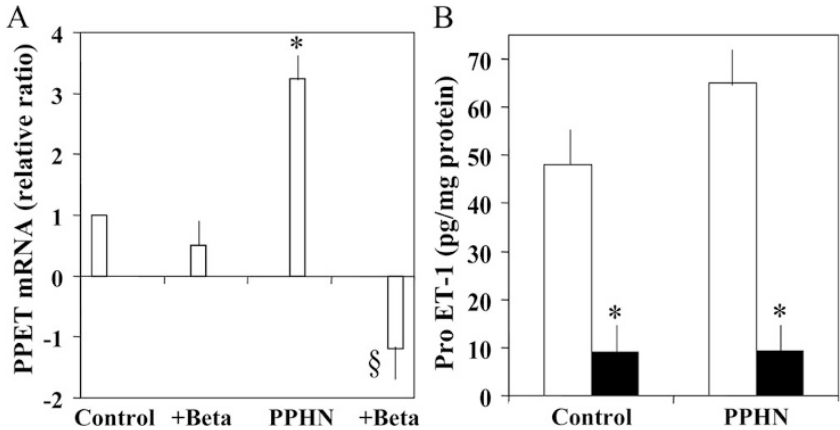

Figure 3. Effect of betamethasone on prepro-endothelin (PPET) mRNA $(A)$ and pro-endothelin-1 (ET-1) peptide $(B)$ in control and PPHN PAEC. In $(A)$, $* p<0.05$ from control PAEC, §from PPHN PAEC. In $(B), * p<0.05$ from basal ET-1 peptide levels; basal $(\square)$ and + betamethasone ( $\square$ )
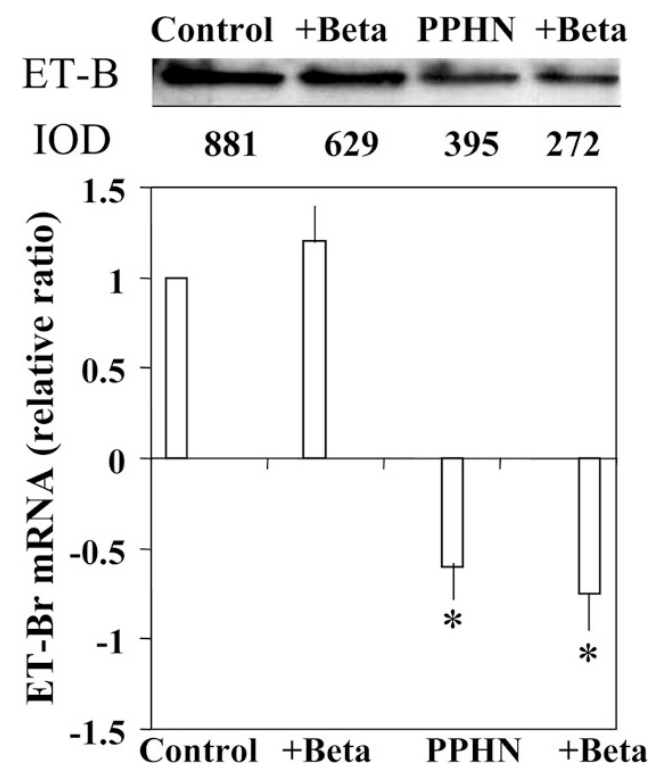

Figure 4. Effect of betamethasone on ET-B receptor mRNA $(A)$ and protein levels, shown as a representative immunoblot $(B) . * p<0.05$ from control PAEC.

ET- B receptor protein level was decreased in PPHN cells and these levels were not altered by betamethasone in PAEC from control or PPHN lambs (Fig. 4B).

SOD expression in PPHN and betamethasone effects. The expression of CuZn SOD was not significantly different in PAEC from PPHN cells compared with control cells (Fig. 5A). The MnSOD expression was decreased in PPHN PAEC (Fig. 5, A and $B$ ). Betamethasone significantly increased the expression of MnSOD in both control and PPHN PAEC (Fig. 5B).

Superoxide levels in PAEC. PAEC from lambs with PPHN had higher DHE fluorescence at baseline compared with control unstimulated PAEC (Figs. 6 and 7). Incubation of control PAEC with the physiologic NOS agonist, ATP did not increase the DHE fluorescence. However, PAEC from lambs with PPHN had a significant increase in DHE fluorescence in response to ATP (Figs. 6 and 7). Betamethasone had no significant effect on DHE fluorescence in the control PAEC. Betamethasone inhibited DHE fluorescence in PAEC from PPHN lambs both at baseline and after exposure to ATP (Figs. 6 and 7). 
A

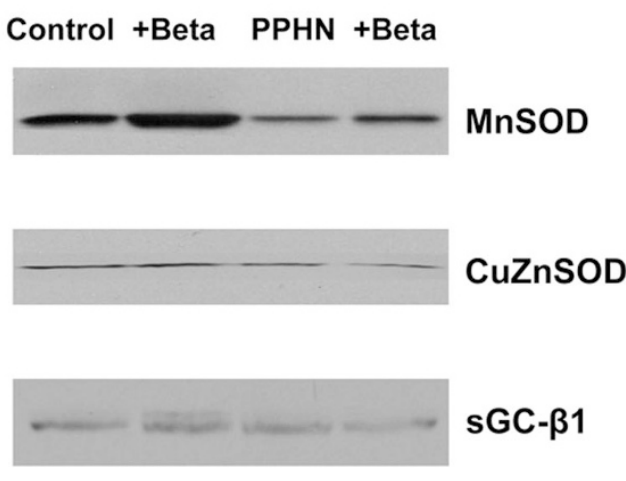

$\mathrm{B}$

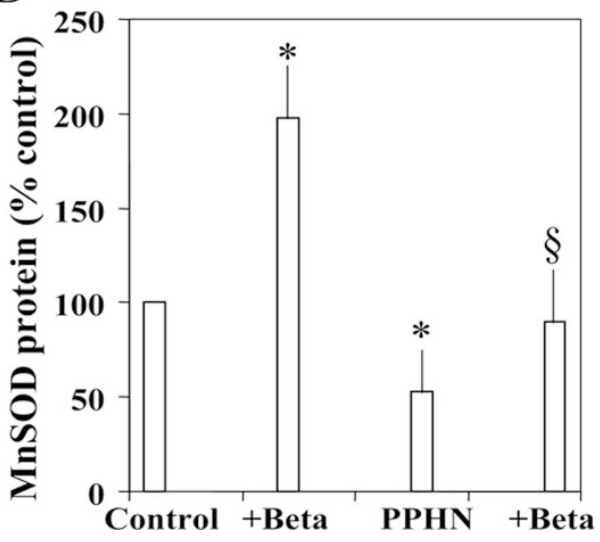

Figure 5. Representative immunoblots of the effects of betamethasone on copperzinc $(\mathrm{CuZn})$ and manganese $(\mathrm{Mn}) \mathrm{SOD}$ and soluble guanylate cyclase (sGC) protein levels in control and PPHN PAEC $(A)$. (B) Summarized data for MnSOD. $* p<$ 0.05 from control PAEC; §from PPHN PAEC.
cGMP levels in PAEC. Expression of soluble guanylate cyclase was not affected by PPHN as we reported previously (12) or by betamethasone (Fig. 5A). Betamethasone treatment resulted in a significant increase in cGMP levels in both control and PPHN cells at basal level (Fig. 8A) and the increases were inhibited by the NOS antagonist L-NAME. Exposure to ATP increased cGMP levels in control but not in PPHN cells (Fig. 8B). Pretreatment with betamethasone in-
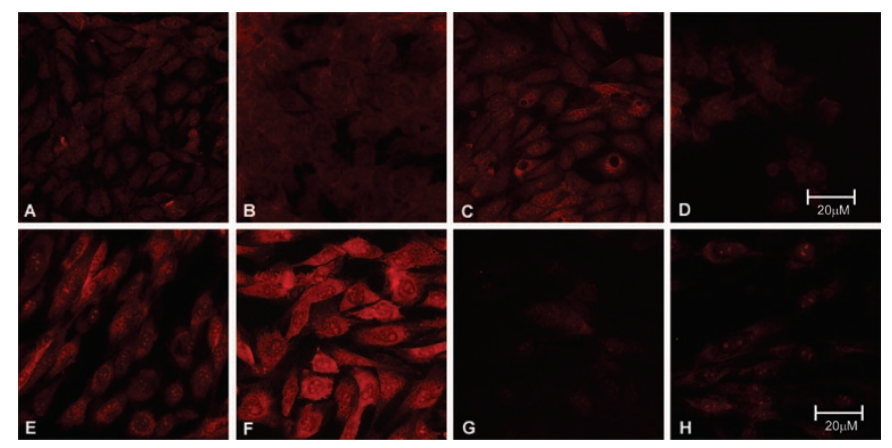

Figure 6. A representative photomicrograph of DHE fluorescence observed in control $(A-D)$ and PPHN $(E-H)$ PAEC. For each group, fluorescence is shown at basal level, in response to ATP, betamethasone alone and betamethasone + ATP in sequence.

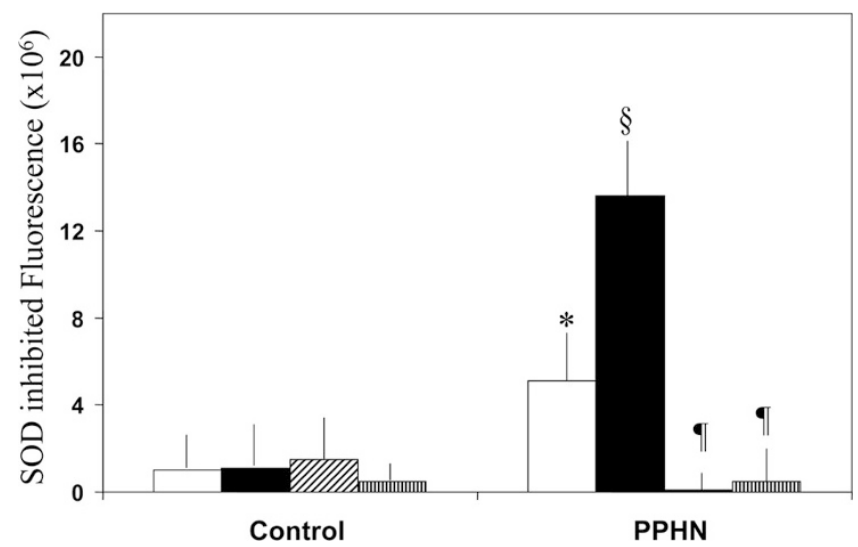

Figure 7. Summarized data for DHE fluorescence observed in control and PPHN PAEC. Only the fluorescence observed above that of wells treated with SOD in each experiment are shown as indicative of $\mathrm{O}_{2}^{-}$levels. ${ }^{*} p<0.05$ from control basal level, §from PPHN basal level, and Ifrom PPHN + ATP. Basal

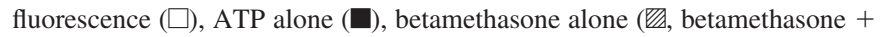
ATP (四). creased the cGMP levels in PPHN cells in response to ATP (Fig. $8 B$ ). Pretreatment of cells with L-NAME inhibited the increase in cGMP levels with ATP in the presence of betamethasone. These data together suggest that betamethasone increases bioavailability of $\mathrm{NO}$ at basal and stimulated conditions in PAEC from PPHN lambs.

Betamethasone effects on Hsp90-eNOS association in $\boldsymbol{P P H N}$. ATP failed to stimulate Hsp90-eNOS interaction (Fig. 9, $A$ and $B$ ) in the PAEC from PPHN lambs, as we reported previously $(12,19)$. Betamethasone treatment restored the response to ATP (Fig. 9, $A$ and $B$ ). These data correlate with the
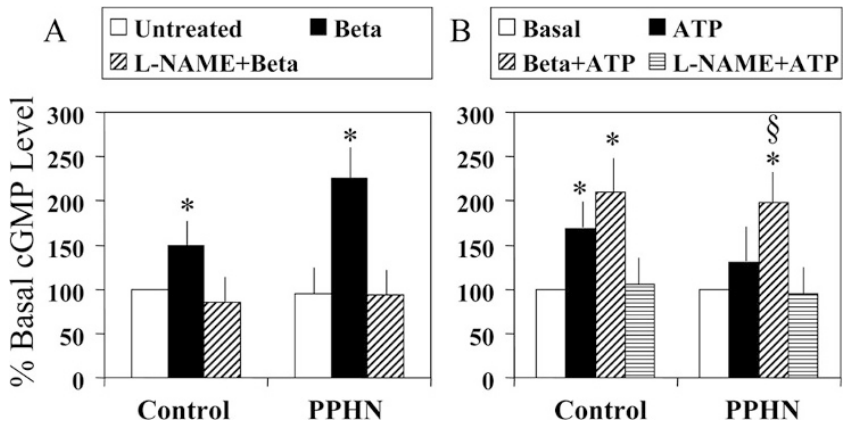

Figure 8. Effect of betamethasone on basal $(A)$ and stimulated $(B)$ cGMP levels in control and PPHN PAEC. Values for control, unstimulated cells were normalized to $100 \%$ and percentage change was shown as mean (SD) for other treatments. $* p<0.05$ from control, §from PPHN + ATP.
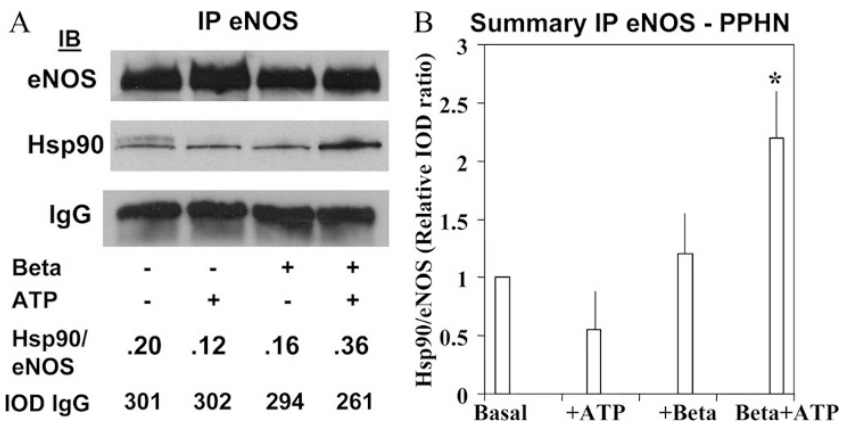

Figure 9. A representative immunoblot $(A)$ and summarized data from four different experiments $(B)$ showing the effect of betamethasone on eNOS-Hsp90 interaction in PPHN cells. The Hsp90/eNOS ratio observed in untreated cells at basal level was normalized to $1 .{ }^{*} p<0.05$ from basal level. 
decrease in $\mathrm{O}_{2}^{--}$and increase in cGMP levels with ATP in hypertensive PAEC treated with betamethasone.

\section{DISCUSSION}

We report that PPHN is associated with increased expression of vasoconstrictor and endothelin and decreased expression of vasodilators, eNOS, ET-Br, and antioxidant, MnSOD. The downstream effect of this altered signaling is an increase in basal and stimulated $\mathrm{O}_{2}^{--}$levels and decreased availability of NO in PPHN. Betamethasone appears to correct these alterations resulting in decreased oxidative stress in PAEC.

A number of previous studies demonstrated an increase in oxidant stress in pulmonary arteries in the ductal ligation model of PPHN. Increase in DHE fluorescence occurs in fetal lamb pulmonary arteries following ductal ligation, accompanied by increases in NADPH oxidase activity and expression (11). An increase in NOS-derived $\mathrm{O}_{2}^{-}$release due to uncoupling of NOS occurs in the endothelial cells of PPHN lambs (12). Uncoupling of eNOS occurs due to decreased Hsp90eNOS interactions (19). The pulmonary arteries from PPHN lambs show improved relaxation responses in the presence of SOD mimetics $(12,19)$. In addition, SOD enhances oxygenation and initiates pulmonary vasodilation in lambs with PPHN (25). These data suggest that oxidant stress in PPHN contributes to the impaired pulmonary vasodilation observed in this condition. The improvement in relaxation response of pulmonary arteries with antenatal betamethasone is probably related to decrease in this oxidative stress in PAEC.

Betamethasone did not increase eNOS transcript in PPHN but increased the protein levels close to control values. These data suggest that betamethasone has posttranscriptional effects on eNOS expression. Betamethasone also increased basal and stimulated cGMP levels in response to ATP, suggesting increased NO availability. These data suggest that the effects of betamethasone on eNOS are nongenomic. In support of this observation, we found that betamethasone improves Hsp90eNOS interactions in hypertensive PAEC in response to ATP. We also observed a decrease in $\mathrm{O}_{2}^{--}$levels with ATP in cells treated with betamethasone. Since uncoupled eNOS is a major source of $\mathrm{O}_{2}^{--}$in PPHN (12), decrease in $\mathrm{O}_{2}^{--}$levels may result from prevention of eNOS uncoupling in hypertensive PAEC.

Our studies show that prepro-endothelin mRNA is significantly increased in PPHN. ET-1 pro-peptide levels showed a trend for increase in PPHN. These data support the previous report of increased ET-1 levels in this model and in babies with PPHN (10). We also observed that the expression of ET-Br, which mediates stimulation of eNOS by ET-1 is decreased in PPHN. These data suggest a coordinated regulation of ET-1 and eNOS in PPHN as previously reported (13). Betamethasone decreased the prepro-endothelin mRNA and ET-1 pro-peptide levels in PAEC. Since ET-1 is a major vasoconstrictor and a pro-oxidant signal in PAEC, these data suggest a potential mechanism for reduction in oxidant stress with betamethasone. We found that betamethasone also decreases ET-1 expression and increases MnSOD expression in control PAEC. These data suggest that betamethasone has general effects on SOD and ET-1 signaling in PAEC and these effects are not specific for PPHN. A potential limitation of our approach is that we used PAEC derived from larger pulmonary arteries. The alterations in microvascular endothelial cells in PPHN and the effects of betamethasone on these alterations may be different from our observations.

Previous studies in fetal lambs and rodents demonstrated that betamethasone enhances the maturation of SOD in the lung. Our studies show that expression of MnSOD, the mitochondrial SOD isoform, is decreased in PPHN, whereas, expression of CuZn SOD is not altered. Previous studies in this model reported no alteration in CuZn- and MnSOD expression, but a decrease in total SOD activity (11). However, these studies were done in lung tissue and homogenized pulmonary arteries. Repeated courses of prenatal glucocorticoids increase antioxidant enzyme activity and reduce oxidative stress in the lungs of preterm lambs (26). This study also demonstrated a greater increase in MnSOD than CuZn SOD expression with betamethasone. SOD enhances vasodilation in response to NOS agonists and NO in the ductal ligation model of PPHN $(12,19)$. These data suggest that betamethasone has multiple biologic effects on pro- and anti-oxidant systems in PAEC, which may account for its effects on vasodilator responses in PPHN.

The dose of betamethasone we used in intact sheep was based on clinically used regimen for antenatal therapy with this agent for preterm labor. The concentration of betamethasone we added to the PAEC for in vitro studies is twice the plasma concentrations measured in pregnant sheep following a single dose of $0.25 \mathrm{mg} / \mathrm{kg}$ (20). Since clinical use of this drug consists of two doses, we chose to add twice the measured concentration initially without addition of subsequent doses during the 48-h period. The fetal plasma concentrations reported in a recent study with a single dose of betamethasone given to the pregnant sheep are $10 \%$ of the maternal concentrations (21). Therefore, the concentration we used for PAEC is approximately 20 -fold higher than fetal plasma levels measured after administration to the mother. However, the fetal tissue concentrations of betamethasone following antenatal therapy are unknown and the distribution of the drug in vivo is more complex than values measured in plasma.

The improvement in the functional response of pulmonary arteries to ATP and NO with prenatal betamethasone suggests that this preventive approach may improve transition at birth for affected infants. However, a limitation to this approach with the current technology is the difficulty in detecting PPHN antenatally. Currently ductal constriction from known exposure to nonsteroidal anti-inflammatory drugs can be recognized by fetal cardiac ultrasonography. Future improvements in ultrasound imaging may permit detection of elevated pulmonary artery pressure to allow antenatal administration of therapies to reduce oxidative stress before birth. Current ongoing trials of antenatal betamethasone for elective cesarean section deliveries at full term or near-term gestation may address the potential efficacy of this agent in decreasing the incidence of PPHN in association with respiratory distress in this population (27). Although babies with congenital diaphragmatic hernia or congenital heart disease are at increased 
risk of pulmonary hypertension, we did not study the effects of betamethasone in these models.

In conclusion, we observed that PPHN is associated with a coordinated and reciprocal regulation of pro- and antioxidant systems in PAEC. Exposure of PAEC to betamethasone decreases oxidant stress and improves eNOS expression and function in PPHN. Antenatal betamethasone improves the pulmonary vascular response to vasodilators in the lamb model of PPHN. The potential translation of this benefit to improved gas exchange and restoration of pulmonary vasodilation in PPHN requires further investigation.

\section{REFERENCES}

1. Abman SH, Chatfield BA, Hall SL, McMurtry IF 1990 Role of endothelium-derived relaxing factor during transition of pulmonary circulation at birth. Am J Physiol 259:H1921-H1927

2. Tiktinsky MH, Morin FC 3rd 1993 Increasing oxygen tension dilates fetal pulmonary circulation via endothelium-derived relaxing factor. Am J Physiol 265:H376H380

3. Konduri GG, Mattei J 2002 Role of oxidative phosphorylation and ATP release in mediating birth-related pulmonary vasodilation in fetal lambs. Am J Physiol Heart Circ Physiol 283:H1600-H1608

4. Konduri GG, Mital S 2000 Adenosine and ATP cause nitric oxide dependent pulmonary vasodilation in fetal lambs. Biol Neonate 78:220-229

5. Lantin-Hermoso RL, Rosenfeld CR, Yuhanna IS, German Z, Chen Z, Shaul PW 1997 Estrogen acutely stimulates nitric oxide synthase activity in fetal pulmonary artery endothelium. Am J Physiol 273:L119-L126

6. Berthiaume N, Yanagisawa M, Yanagisawa H, deWit D, D’Orleans-Juste P 1998 Pharmacology of endothelins in vascular circuits of normal or heterozygous endothelin-A or endothelin-B knockout transgenic mice. J Cardiovasc Pharmacol 31:S561-S564

7. Wedgwood S, McMullan DM, Bekker JM, Fineman JR, Black SM 2001 Role of endothelin-1-induced superoxide and peroxynitrite production in rebound pulmonary hypertension associated with inhaled nitric oxide therapy. Circ Res 89:357-364

8. Wedgwood S, Dettman RW, Black SM 2001 ET-1 stimulates pulmonary arterial smooth muscle cell proliferation via induction of reactive oxygen species. Am J Physiol Lung Cell Mol Physiol 281:L1058-L1067

9. Shaul PW, Yuhanna IS, German Z, Chen Z, Steinhorn RH, Morin FC 3rd 1997 Pulmonary endothelial NO synthase gene expression is decreased in fetal lambs with pulmonary hypertension. Am J Physiol 272:L1005-L1012

10. Rosenberg AA, Kennaugh J, Koppenhafer SL, Loomis M, Chatfield BA, Abman SH 1993 Elevated immunoreactive endothelin-1 levels in newborn infants with persistent pulmonary hypertension. J Pediatr 123:109-114
11. Brennan LA, Steinhorn RH, Wedgwood S, Mata-Greenwood E, Roark EA, Russell JA, Black SM 2003 Increased superoxide generation is associated with pulmonary hypertension in fetal lambs: a role for NADPH oxidase. Circ Res 92:683-691

12. Konduri GG, Bakhutashvili I, Eis A, Pritchard KA 2007 Oxidant stress from uncoupled nitric oxide synthase impairs vasodilation in fetal lambs with persistent pulmonary hypertension. Am J Physiol Heart Circ Physiol 292:H1812-H1820

13. Black SM, Johengen MJ, Soifer SJ 1998 Coordinated regulation of genes of the nitric oxide and endothelin pathways during the development of pulmonary hypertension in fetal lambs. Pediatr Res 44:821-830

14. Ivy DD, Parker TA, Ziegler JW, Galan HL, Kinsella JP, Tuder RM, Abman SH 1997 Prolonged endothelin A receptor blockade attenuates chronic pulmonary hypertension in the ovine fetus. J Clin Invest 99:1179-1186

15. Sadowska AM, Klebe B, Germonpre P, De Backer WA 2007 Glucocorticosteroids as antioxidants in treatment of asthma and COPD. New application for an old medication? Steroids $72: 1-6$

16. Frank L, Lewis PL, Sosenko IR 1985 Dexamethasone stimulation of fetal rat lung antioxidant enzyme activity in parallel with surfactant stimulation. Pediatrics 75:569-574

17. Walther FJ, David-Cu R, Mehta EI, Polk DH, Jobe AH, Ikegami M 1996 Higher lung antioxidant enzyme activity persists after single dose of corticosteroids in preterm lambs. Am J Physiol 271:L187-L191

18. Gao Y, Tolsa JF, Shen H, Raj JU 1998 A single dose of antenatal betamethasone enhances isoprenaline and prostaglandin E2-induced relaxation of preterm ovine pulmonary arteries. Biol Neonate 73:182-189

19. Konduri GG, Ou J, Shi Y, Pritchard KA Jr 2003 Decreased association of HSP90 impairs endothelial nitric oxide synthase in fetal lambs with persistent pulmonary hypertension. Am J Physiol Heart Circ Physiol 285:H204-H211

20. Samtani MN, Lohle M, Grant A, Nathanielsz PW, Jusko WJ 2005 Betamethasone pharmacokinetics after two prodrug formulations in sheep: implications for antenatal corticosteroid use. Drug Metab Dispos 33:1124-1130

21. Schwab M, Coksaygan T, Samtani MN, Jusko WJ, Nathanielsz PW 2006 Kinetics of betamethasone and fetal cardiovascular adverse effects in pregnant sheep after different doses. Obstet Gynecol 108:617-625

22. Pfaffl MW 2001 A new mathematical model for relative quantification in real-time RT-PCR. Nucleic Acids Res 29:e45

23. Garcia-Cardena G, Fan R, Shah V, Sorrentino R, Cirino G, Papapetropoulos A, Sessa WC 1998 Dynamic activation of endothelial nitric oxide synthase by Hsp90. Nature 392:821-824

24. Pritchard KA Jr, Ackerman AW, Gross ER, Stepp DW, Shi Y, Fontana JT, Baker JE, Sessa WC 2001 Heat shock protein 90 mediates the balance of nitric oxide and superoxide anion from endothelial nitric-oxide synthase. J Biol Chem 276:1762117624

25. Steinhorn RH, Albert G, Swartz DD, Russell JA, Levine CR, Davis JM 2001 Recombinant human superoxide dismutase enhances the effect of inhaled nitric oxide in persistent pulmonary hypertension. Am J Respir Crit Care Med 164:834-839

26. Walther FJ, Jobe AH, Ikegami M 1998 Repetitive prenatal glucocorticoid therapy reduces oxidative stress in the lungs of preterm lambs. J Appl Physiol 85:273-278

27. Stutchfield P, Whitaker R, Russell I Antenatal Steroids for Term Elective Caesarean Section (ASTECS) Research Team 2005 Antenatal betamethasone and incidence of neonatal respiratory distress after elective caesarean section: pragmatic randomised trial. BMJ 331:662-667 